\title{
KORELASI DAN ANALISIS LINTAS ANTARA PERCABANGAN DENGAN PRODUKSI CABAI MERAH (Capsicum annuum L.) HASIL IRADIASI SINAR GAMMA
}

\author{
CORRELATION AND CROSS-SECTIONAL ANALYSIS BETWEEN \\ BRANCHING AND PRODUCTION OF GAMMA RAY IRRADIATED \\ RED CHILI (Capsicum annuum L.)
}

\author{
Nyimas Sa'diyah' Anissa Fitri, Rugayah, Agus Karyanto \\ Jurusan Agroteknologi, Fakultas Pertanian, Universitas Lampung \\ Jl. Prof. Soemantri Brodjonegoro No. 1 Bandar Lampung 35145 \\ Email:nyimas_diyah@yahoo.com
}

\begin{abstract}
The productivity of red chili in Indonesia is about 8.35 tons per year, lower than its potential which is 22 tons per year. To increase red chili production, improving plant material through mutations with gamma ray irradiation can be done. Furthermore, to shorten the selection time, it is necessary to study the relationship between variables with correlation analysis, to see the direct and indirect effects of crosssectional analysis. This study aimed to determine the relationship between M3 generation of red chili (Laris variety) branching exposed to gamma ray irradiation with its production. This research conducted in September 2018 until May 2019 at the Integrated Field Laboratory, Faculty of Agriculture, Lampung University. The experiment designed with single plant method (all plants were planted and observed), correlation analysis was used to determine the strength of relationship between variables, cross-sectional analysis was used to see the direct and indirect effects. The results showed that: the number of additional branches, length of additional branches, branching rate, plant height at the end of generative phase, and number of chili per plant were positively correlated with total chili weight per plant. Plant height at the end of generative phase, number of additional branches, length of additional branches, and branching rates influenced each other to increased chili weight per plant or production.
\end{abstract}

Keywords : Branching, correlation, cross-sectional analysis, mutation, red chili.

\begin{abstract}
ABSTRAK
Produktivitas cabai merah di Indonesia masih sangat rendah jika dibandingkan dengan potensinya yang mencapai 22 ton per tahun, sedangkan produktivitas baru sekitar 8,35 ton per tahun. Peningkatan produksi cabai merah dapat dilakukan dengan memperbaiki bahan tanam melalui mutasi dengan iradiasi sinar gamma. Selanjutnya,untuk mempersingkat waktu seleksiperlu dilihat keeratan hubungan antarpeubah dengan analisis korelasi, untuk melihat pengaruh langsung dan tidak langsungnya dilakukan analisis lintas. Penelitian ini bertujuan untuk mengetahui hubungan antara percabangan cabai merah varietas Laris generasi $\mathrm{M}_{3}$ hasil iradiasi sinar gamma dengan produksi.
\end{abstract}


Penelitian ini dilaksanakan pada bulan September 2018 sampai dengan Mei 2019 di Laboratorium Lapang Terpadu, Fakultas Pertanian, Universitas Lampung. Rancangan percobaan yang digunakan adalah metode single plant (seluruh tanaman ditanam dan diamati), keeratan hubungan dianalisisdengan korelasi, selanjutnya untuk melihat pengaruh langsung dan tidak langsung dilakukan analisis lintas. Hasil penelitian menunjukkan bahwa: jumlah cabang tambahan, panjang cabang tambahan, tingkat percabangan, tinggi akhir generatif, dan jumlah buah per tanaman berkorelasi positif denganbobot buah total per tanaman Pengaruh langsung jumlah buah per tanaman benar-benar mengukur keeratan hubungan dengan bobot buah per tanaman. Tinggi akhir generatif, jumlah cabang tambahan, panjang cabang tambahan, dan tingkat percabangan saling berpengaruh satu sama lain untuk mempengaruhi bobot buah per tanaman atau produksi.

Kata kunci: Analisis lintas,cabai merah,korelasi, mutasi, percabangan.

Cabai (Capsicum annuum L.) adalah salah satu komoditas hortikultura yang penting dan bernilai ekonomi di Indonesia. Cabai memiliki keragaman dalam bentuk buah, warna buah, tipe buah, rasa dan kandungan biokimia lainnya (Sulassih dkk., 2017). Berdasarkan data yang dikeluarkan Badan Pusat Statistik (2017), produksi cabai nasional mengalami peningkatan dari tahun 2016 yaitu sebesar 1.045. 601 ton dengan luas panen 120.847 ha menjadi 1.206. 266 ton dengan luas panen 142.366 ha pada tahun 2017, ini artinya kenaikan produksi cabai merah dalam kurun waktu 2016 ke 2017 mencapai 15,36\%. Meskipun demikian, menurut Rofidah dkk. (2018), produktivitas cabai merah di Indonesia masih rendah, rata-rata nasional hanya 8,35 ton/ha, sedangkan potensinya dapat mencapai 22 ton/ha.

Berdasarkan hal tersebut perlu dilakukan upaya perbaikan terhadap produksi cabai merah melalui pemuliaan tanaman. Perbaikan produksi cabai diperlukan keragaman pada produksi cabai merah. Keragaman dapat ditingkatkan dengan mutasi. Menurut Purba dkk. (2013), mutagen yang sering digunakan adalah sinar gamma. Sinar gamma mempunyai kemampuan penetrasi yang cukup kuat ke dalam jaringan. Kualitas cabai yang baik dilihat dari tinggi tanaman yang proporsional, mempunyai banyak cabang, dan banyak buah (Widiatmoko dkk., 2016). Menurut Sidiq dkk (2017) pada cabai rawit generasi $M_{3}$ terdapat 10 genotipe terbaik yang memiliki produksi tinggi dibandingkan dengan populasi awalnya.Analisis lintas digunakan untuk memilah korelasi peubah pertumbuhan dengan produksi cabai menjadi pengaruh langsung dan tidak langsung (Murniati dkk., 2013).

Percabangan pada tanaman cabai berpengaruh terhadap produksi, sehingga diduga akan berkorelasi dengan produksi. Berdasarkan hal tersebut, dilakukan analisis korelasi antarvariabel. Seleksi akan efektif apabila antarvariabel berkorelasi.Korelasi tidak dapat mengetahui pengaruh langsung dan tidak langsung, sedangkan analisis lintas dapat mengetahui pengaruh langsung dan tidak langsung antara faktor penyebab (kausal) dan faktor yang dipengaruhi (efek) (Yunianti, dkk., 2010) . Tujuan penelitian ini adalah untuk mengetahui korelasi antarapercabangan dan produksi 
maupun tidak langsung percabangan dengan produksi. pada tanaman cabai serta melihat pengaruh langsung

\section{BAHAN DAN METODE}

Penelitian ini dilaksanakandi Laboratorium Lapang Terpadu, Fakultas Pertanian, Universitas Lampungyang memiliki ketinggian tempat $<100$ mdpl. Pelaksanaan penelitian ini mulai dari September 2018 sampai dengan Mei 2019. Benih yang digunakan adalah benih $\mathrm{M}_{2-112}$. Sebelumnya benih $\mathrm{M}_{2}$ merupakan benih hasil iradiasi sinar gamma di Pusat Penelitian dan Pengembangan Teknologi Isotop dan Radiasi, Pasar Jum'at, Jakarta pada tanggal 15 Juni 2016.Dosis terbaik pada $M_{1}$ yakni 400 Gy.Benih yang diradiasi adalah varietas Laris. Benih tersebut ditanam pada petak ukuran 3,8m x $5 \mathrm{~m}$. Rancangan percobaan yang digunakan adalah metode single plant (seluruh tanaman ditanam dan diamati)

Penyemaian dilakukan dengan menanam benih cabai pada campuran tanah dan pupuk kandang dengan perbandingan 1:1.Bibit cabai ditanam pada guludan dengan ukuran $1 \mathrm{~m}$ x $12 \mathrm{~m}$ dan diberi mulsa plastik perak. Jarak tanam $50 \mathrm{~cm}$ x $70 \mathrm{~cm}$ dan setiap lubang tanam diberi pupuk kandang 150 g. Pemupukan dilakukan sebanyak dua kali yakni pada masa vegetatif dan masa generatif menggunakanpupuk NPK mutiara dengan dosis 6,38 g/500 $\mathrm{ml}$ air setiap kali pemupukan. Pengendalian OPT dilakukan secara rutin, penggunaan perangkap kuning dan perangkap hormon untuk lalat buah serta fungisida untuk kemungkinan serangan jamur sesuai dosis anjuran. Pemanenan dilakukan seminggu dua kali terhadap buah yang sudah berwarna merah.
Variabel pengamatan yang diamati adalah bobot buah total per tanaman, jumlah buah total per tanaman, jumlah percabangan (primer, sekunder, tersier, quarter, dan tambahan), panjang percabangan (primer, sekunder, tersier, quarter, dan tambahan), tinggi tanaman(awal generatif dan akhir waktu panen selama 40 hari), dan tingkat percabanganUntuk mengetahui hubungan antar karakter dilakukan analisis korelasi sederhana dengan menggunakan rumus sebagai berikut:

$$
r_{x y}=\frac{n \Sigma X_{i} Y_{i}-\left(\Sigma X_{i}\right)\left(\Sigma Y_{i}\right)}{\sqrt{\left[n \Sigma X_{i}^{2}-\left(\Sigma X_{i}\right)^{2}\right]\left[n \Sigma Y_{i}{ }^{2}-\left(\Sigma Y_{i}\right)^{2}\right]}}
$$

Keterangan :

$$
\begin{aligned}
& \mathrm{r}_{\mathrm{xy}}=\text { korelasi antara variabel } \mathrm{x} \text { dan } \mathrm{y} \\
& \mathrm{x}=\text { variabel } \mathrm{X} \\
& \mathrm{y}=\text { variabel } \mathrm{Y} \\
& \mathrm{n}=\text { jumlah Pengamatan } \\
& t-\text { hit }=\frac{r \sqrt{n-2}}{\sqrt{1-r^{2}}}
\end{aligned}
$$

Apabila nilai t hitung $>$ t tabel $5 \%$ bermakna nyata, thitung $>$ t tabel $1 \%$ bermakna sangat nyata, thitung $<$ t tabel bermakna tidak nyata.

Untuk melihat pengaruh langsungvariabel $\mathrm{X}$ dan Y dapat dihitung denganmenggunakan rumus sebagai berikut:

$$
C=\left(R_{x}\right)^{-1}\left(R_{Y}\right)
$$

Dalam bentuk matriks rumust tersebut sebagai berikut:

$$
\underset{\left.\begin{array}{cccc}
r_{11} & r_{12} & \ldots & r_{1 p} \\
r_{21} & r_{22} & \ldots & r_{2 p} \\
\ldots & \ldots & \ldots & \ldots \\
\ldots & \ldots & \ldots & \ldots \\
r_{p 1} & r_{p 2} & \ldots & r_{p p}
\end{array}\right]}{\left[\begin{array}{c}
C_{1} \\
C_{2} \\
\ldots \\
R_{x}
\end{array}\right]} \underset{C_{i}}{\left[\begin{array}{c}
r_{1 y} \\
C_{2 y} \\
\ldots \\
C_{p}
\end{array}\right]} \underset{R_{y}}{\left[\begin{array}{c}
{[} \\
r_{p y}
\end{array}\right]}
$$


Keterangan:

$\mathrm{R}_{\mathrm{X}} \quad=$ Matriks korelasi antar sifat agronomi yang diamati $\mathrm{R}_{\mathrm{XIXj}}(\mathrm{i}, \mathrm{j}=1,2, \ldots \mathrm{n})$

$\mathrm{C}=$ Matriks koefisien pengaruh langsung $\mathrm{X}_{\mathrm{i}}$ terhadap $Y(I=1,2, \ldots n)$

$\mathrm{R}_{\mathrm{Y}} \quad=$ Matriks koefisien korelasi terhadap $\mathrm{X}_{\mathrm{i}}$ terhadap $Y(i=1,2, \ldots n)$

$\mathrm{R}_{\mathrm{x}}^{-1} \quad=$ Invers matiks $\mathrm{R}_{\mathrm{x}}$

Pengaruh tidak langsung suatu peubah $\mathrm{x}_{\mathrm{i}}$ melalui peubah $\mathrm{x}_{\mathrm{j}}$ terhadap vektor $\mathrm{Y}$ dihitung dengan rumus:

Keterangan:

$$
\mathbf{P}_{\mathrm{ij}}=\mathbf{r}_{\mathrm{ij}} \mathbf{P}_{\mathrm{j}}
$$

$\mathrm{r}_{\mathrm{ij}}=$ korelasi antara komponen ke-i dengan komponen ke-j

$\mathrm{P}_{\mathrm{ij}} \quad=$ Pengaruh tidak langsung suatu peubah $\mathrm{X}_{\mathrm{i}}$ melalui peubah ke $\mathrm{X}_{\mathrm{j}}$ melalui peubah $\mathrm{ke} \mathrm{X}_{\mathrm{j}}$ terhadap vektor $Y$

$\mathrm{P}_{\mathrm{j}} \quad=$ koefisien lintas komponen ke $\mathrm{j}$ terhadap hasil

Penafsiran koefisien lintas dapat dilakukan berdasarkan tiga pedoman Singh dan Chaudary (1979) yaitu: 1. Korelasi akan benar-benar mengukur derajat keeratan hubungan antara $\mathrm{X}$ dan $\mathrm{Y}$, apabila korelasi $\mathrm{X}$ dan Y hampir sama besar dengan pengaruh langsung;

2. Korelasi disebabkan oleh pengaruh tak langsung, apabila korelasi X dan Y bernilai positiftetapi pengaruh langsung negatif atau dapat diabaikan; 3. Batasi efek tak langsung yang tidak dikehendaki sehingga dalam penafsirannya dapat benar-benar memanfaatkan efek langsung, apabila korelasi X dan Y bernilai negatif tetapi pengaruh langsung bernilai positif dan besar

\section{HASIL DAN PEMBAHASAN}

Hasil penelitian menunjukkan bahwa percabangan memiliki korelasi dengan beberapa karakter agronomi dan utamanya terhadap bobot buah total per tanaman atau produksi (Tabel 1). Jumlah cabang sekunder berkorelasi positif sangat nyata dengan jumlah cabang tersier dan jumlah cabang quarter pada nilai berturut-turut 0,85 dan 0,75. Korelasi positif jumlah cabang tersier dan jumlah cabang quarter sebesar 0,86 , berarti makin banyak cabang sekunder maka makin banyak cabang tersier, juga guarter. Tingkat percabangan berkorelasi positif sangat nyata dengan jumlah cabang tambahan dan tinggi akhir tanaman dengan nilai berturut-turut sebesar 0,55 dan 0,52 . Hal ini menunjukkan bahwa makin tinggi tanaman, maka jumlah cabang tambahan dan tingkat percabangan makin banyak. Menurut Aditya dkk. (2013) tinggi tanaman yang kurang maksimal mempengaruhi tingkat percabangan dan jumlah cabang yang akan berpengaruh pada jumlah bunga.

Panjang cabang primer berkorelasi positif sangat nyata dengan panjang cabang sekunder sebesar 0,55. Panjang cabang sekunder berkorelasi kuat sangat nyata dengan panjang cabang tersier sebesar 0,73 . Panjang cabang tersier berkorelasi sangat nyata dengan panjang cabang quarter sebesar 0,65 . Panjang cabang primer berkorelasi positif sangat nyata dengan panjang cabang tersier, dan panjang cabang quarter sebesar 0,48 dan 0,33. Panjang cabang sekunder dengan panjang cabang quarter sebesar 0,41 . Menurut Murniati dkk. (2013) tinggi tanaman mempengaruhi hasil fotosintesis, tinggi tanaman cabai merupakan kombinasi dari panjang cabang pada tingkatannya yang kemudian akan membentuk tajuk tanaman dengan jumlah daun yang ada. Semakin panjang cabang memungkinkan tanamansemakin tinggi atau semakin 
Tabel 1. Nilai koefisien korelasi antarkarakter

\begin{tabular}{|c|c|c|c|c|c|c|c|c|c|c|c|c|c|c|c|c|}
\hline Peubah & 1 & 2 & 3 & 4 & 5 & 6 & 7 & 8 & 9 & 10 & 11 & 12 & 13 & 14 & 15 & 16 \\
\hline 1 & & $10,95 * *$ & $0,20^{\text {tn }}$ & $0,45 * *$ & $-0,14^{\operatorname{tn}}$ & $-0,15^{\operatorname{tn}}$ & $-0,15^{\mathrm{tn}}$ & $-0,06^{\mathrm{tn}}$ & $0,41 * *$ & $-0,10^{\operatorname{tn}}$ & $-0,11^{\text {tn }}$ & $0,02^{\operatorname{tn}}$ & $0,03^{\text {tn }}$ & $0,45^{* *}$ & $-0,00^{\text {tn }}$ & $0,22^{*}$ \\
\hline 2 & & & $10,21^{*}$ & $0,37 * *$ & $-0,14^{\mathrm{tn}}$ & $-0,15^{\text {tn }}$ & $-0,16^{\mathrm{tn}}$ & $-0,07^{\mathrm{tn}}$ & $0,37 * *$ & $-0,10^{\operatorname{tn}}$ & $-0,12^{\text {tn }}$ & $0,01^{\operatorname{tn}}$ & $0,05^{\operatorname{tn}}$ & $0,42 * *$ & $0,01^{\mathrm{tn}}$ & $0,15^{\mathrm{tn}}$ \\
\hline 3 & & & & $10,32 * *$ & $0,07^{\mathrm{tn}}$ & $0,10^{\operatorname{tn}}$ & $0,15^{\operatorname{tn}}$ & $0,09^{\operatorname{tn}}$ & $0,04^{\operatorname{tn}}$ & $0,16^{\operatorname{tn}}$ & $0,06^{\operatorname{tn}}$ & $0,13^{\operatorname{tn}}$ & $0,08^{\text {tn }}$ & $0,03^{\operatorname{tn}}$ & $-0,29^{\mathrm{tn}}$ & $0,21 *$ \\
\hline 4 & & & & & $1-0,02^{\text {tn }}$ & $-0,00^{\mathrm{tn}}$ & $-0,00^{\text {tn }}$ & $0,09^{\operatorname{tn}}$ & $0,47^{* *}$ & $0,20^{\operatorname{tn}}$ & $0,13^{\operatorname{tn}}$ & $0,23^{*}$ & $0,24^{*}$ & $0,51 * *$ & $-0,19^{\operatorname{tn}}$ & $0,52 * *$ \\
\hline 5 & & & & & & $10,93 * *$ & $0,82 * *$ & $0,74 * *$ & $0,11^{\mathrm{tn}}$ & $-0,12^{\mathrm{tn}}$ & $0,21^{*}$ & $0,13^{\operatorname{tn}}$ & $0,06^{\mathrm{tn}}$ & $-0,21^{\mathrm{tn}}$ & $-0,00^{\mathrm{tn}}$ & $0,11^{\mathrm{tn}}$ \\
\hline 6 & & & & & & & $10,85^{* *}$ & $0,75^{* *}$ & $0,06^{\text {tn }}$ & $-0,12^{\operatorname{tn}}$ & $0,22^{*}$ & $0,15^{\mathrm{tn}}$ & $0,08^{\mathrm{tn}}$ & $-0,19^{\text {tn }}$ & $-0,01^{\mathrm{tn}}$ & $0,04^{\text {tn }}$ \\
\hline 7 & & & & & & & & $10,86^{* *}$ & $0,11^{\mathrm{tn}}$ & $0,07^{\mathrm{tn}}$ & $0,33 * *$ & $0,23^{*}$ & $0,16^{\mathrm{tn}}$ & $-0,23^{\text {tn }}$ & $-0,03^{\text {tn }}$ & $0,08^{\text {tn }}$ \\
\hline 8 & & & & & & & & & $10,19^{\operatorname{tn}}$ & $0,12^{\mathrm{tn}}$ & $0,37 * *$ & $0,22 *$ & $0,21 *$ & $-0,06^{\mathrm{tn}}$ & $0,13^{\text {tn }}$ & $0,08^{\mathrm{tn}}$ \\
\hline 9 & & & & & & & & & & $10,02^{\operatorname{tn}}$ & $-0,04^{\mathrm{tn}}$ & $-0,11^{\mathrm{tn}}$ & $-0,05^{\mathrm{tn}}$ & $0,05^{\mathrm{tn}}$ & $-0,11^{\mathrm{tn}}$ & $0,55^{* *}$ \\
\hline 10 & & & & & & & & & & & $10,55^{* *}$ & $0,48 * *$ & $0,33 * *$ & $0,14^{\operatorname{tn}}$ & $-0,08^{\operatorname{tn}}$ & $0,03^{\operatorname{tn}}$ \\
\hline 11 & & & & & & & & & & & & $10,73^{* *}$ & $0,39 * *$ & $0,06^{\operatorname{tn}}$ & $-0,02^{\operatorname{tn}}$ & $-0,04^{\mathrm{tn}}$ \\
\hline 12 & & & & & & & & & & & & & $0,65^{* *}$ & $0,27 * *$ & $-0,16^{\mathrm{tn}}$ & $-0,03^{\text {tn }}$ \\
\hline 13 & & & & & & & & & & & & & & $10,35^{* *}$ & $-0,23^{\mathrm{tn}}$ & $-0,04^{\text {tn }}$ \\
\hline 14 & & & & & & & & & & & & & & & $10,04^{\mathrm{tn}}$ & $-0,11^{\text {tn }}$ \\
\hline 15 & & & & & & & & & & & & & & & & $1-0,23^{\text {tn }}$ \\
\hline 16 & & & & & & & & & & & & & & & & \\
\hline
\end{tabular}

Keterangan:

1. Bobot buah total 9. Jumlah cabang tambahan

2. Jumlah buah total 10. Panjang cabang primer

3. Tinggi awal generatif 11. Panjang cabang sekunder

4. Tinggi akhir generatif 12. Panjang cabang tersier

5. Jumlah cabang primer 13. Panjang cabang quarter

6. Jumlah cabang sekunder 14. Panjang cabang tambahan

7. Jumlah cabang tersier 15. Masa panen selama 40 hari

8. Jumlah cabang quarter 16. Tingkat percabangan

$* *=$ Sangat nyata pada taraf $1 \% ; *=$ Nyata pada taraf $5 \%$; th $=$ tidak nyata pada taraf $1 \%$ dan 5

lebar tajuknya sehingga sinar matahari banyak terserap dan fotosintesis menjadi optimal.

Bobot buah total per tanaman berkorelasi positif nyata dengan tingkat percabangan dengan nilai 0,21. Pada karakter jumlah cabang memiliki keeratan yang tinggi satu sama lainnya, hal ini ditunjukkan pada hasil nilai korelasi positif sangat nyata antara jumlah cabang primer dengan jumlah cabang sekunder,jumlah cabang tersier, dan jumlah cabang quarter berturut-turut sebesar 0,$93 ; 0,82$ dan 0,74 . Bobot buah total per tanaman berkorelasi positif sangat nyata dengan karakter tinggi akhir generatif sebesar 0,45 . Semakin banyak jumlah cabang primer maka akan dikuti dengan makin banyaknya jumlah cabang sekunder juga tersier. Kemudian diikuti dengan tinggi tanaman yang makin tinggi maka tingkat percabangan juga semakin banyak yang pada akhirnya bobot buah juga semakin tinggi.Hasil penelitian Rofidah dkk. (2018) karakter tinggi tanaman berkorelasi sangat nyata dengan bobot buah per tanaman sebesar 0,80 . Tanaman yang tinggi akan mendapatkan supply cahaya matahari yang optimum daripada tanaman yang pendek sehingga memungkinkan proses fotosintesis lebih optimum dan menghasilkan hasil buah cabai yang banyak.

Jumlah cabang tambahan (seluruh jumlah cabang setelah cabang quarter) memiliki korelasi positif sangat nyata dengan jumlah buah total dan bobot buah total berturut-turut sebesar 0,37 dan 0,41. Hasil penelitian ini sama dengan hasil penelitian pada tanaman kedelai, menurut hasil penelitian Muzaiyanah dan 
Tabel 2. Matriks analisis lintas fenotipe berbagai karakter pengamatan dengan bobot buah total per tanaman

\begin{tabular}{|c|c|c|c|c|c|c|c|c|}
\hline \multirow{2}{*}{$\begin{array}{c}\text { Peubah bebas } \\
\text { yang dilakukan }\end{array}$} & \multirow{2}{*}{$\begin{array}{l}\text { Pengaruh } \\
\text { langsung }\end{array}$} & \multicolumn{5}{|c|}{ Pengaruh tidak langsung melalui peubah } & \multirow{2}{*}{$\begin{array}{l}\text { Total pengaruh tidak } \\
\text { langsung }\end{array}$} & \multirow{2}{*}{$\begin{array}{c}\text { Korelasi dengan bobot } \\
\text { buah per tanaman }\end{array}$} \\
\hline & & 1 & 2 & 3 & 4 & 5 & & \\
\hline 1 & 0,89 & & 0,02 & 0,01 & 0,02 & 0,01 & 0,06 & 0,95 \\
\hline 2 & 0,06 & 0,33 & & 0,01 & 0,03 & 0,03 & 0,39 & 0,45 \\
\hline 3 & 0,02 & 0,33 & 0,03 & & 0 & 0,03 & 0,39 & 0,41 \\
\hline 4 & 0,05 & 0,37 & 0,03 & 0 & & $-0,01$ & 0,4 & 0,45 \\
\hline 5 & 0,05 & 0,13 & 0,03 & 0,01 & $-0,01$ & & 0,2 & 0,22 \\
\hline
\end{tabular}

Keterangan: $1=$ Jumlah buah total ; 2.= Tinggi akhir generatif; $3=$ Jumlah cabang tambahanr; $4=$ Panjang cabang tambahan $5=$ Tingkat percabangan

Santoso (2016) jumlah cabang memiliki korelasi positif sangat nyata dengan bobot biji kedelai dan jumlah polong isi berturut-turut sebesar 0,58 dan 0,59 , dengan demikian dapat diasumsikan bahwa semakin banyak jumlah cabang tanaman kedelai maka akan semakin banyak jumlah polong isi dan bobot buah total. Begitu pula percabangan tanaman cabai, setiap percabangan akan muncul bunga dan kemudian menjadi buah.

Bobot buah total berkorelasi sangat nyata dengan jumlah buah total per tanaman dengan nilai 0,95 . Hal ini didukung oleh hasil penelitian Rofidah dkk. (2018) bahwa korelasi antara jumlah buah total dengan bobot buah total per tanaman sebesar 0,95. Jumlah buah total berkorelasi positif sangat nyata dan nyata dengan tinggi akhir generatif dan tinggi awal generatif sebesar 0,23 dan 0,37. Berarti dengan semakin banyaknya jumlah buah, maka bobot buah juga akan semakin berat. Hal ini juga didukung oleh hasil penelitian Rofidah dkk. (2018) adanya korelasi antara jumlah buah total dan tinggi tanaman sebesar 0,23. Tinggi tanaman dapat membantu tanaman mendapatkan cahaya matahari untuk fotosintesis. Proses fotosintesis dipengaruhi oleh ketersediaan klorofil, air dan cahaya.

Korelasi melihat keeratan hubungan antarvariebel, sedangkan analisis lintas menjelaskan konstribusi relatif dari masing-msing variabel terhadap hasil, baik secara langsung maupun tidak langsung (Lelang, 2017). Variabel-variabel yang tidak berkorelasi dengan bobot buah per tanaman tidak disertakan pada analisis lintas (Lelang, 2017). Pengaruh langsung dan tidak lang sung dari masing-masing variabel dengan dengan bobot buah per tanaman (Tabel 2) dapat ditafsirkan dengan menggunakan pedoman Singh danChaudary (1979). Berdasarkanpedomantersebut, jumlah buah total per tanamanmempunyai pengaruh langsung positif terhadap bobot buah sebesar $(0,89)$. Berarti pengaruh langsungjumlah buah total per tanamanbenar-benar menunjukkan keeratan hubungan variabel tersebut dengan bobot buah per tanaman. Tinggi akhir generatif, jumlah cabang tambahan, panjang cabang tambahan, dan tingkat percabangan, memenuhi pedoman ke dua. Pedoman ke dua Singh dan Chaudary, (1979), menyatakan bahwa korelasi disebabkan oleh pengaruh tak langsung, Hal itu 
menunjukkan bahwa hubungan antara tinggi akhir generatif terhadap bobot buah total per tanaman lebih disebabkan oleh tiga variabel yang lain yaitu jumlah cabang tambahan, panjang cabanag tamabahan dan tingkat percabanagan, demikian juga dengan jumlah cabang tambahan, panjang cabang tambahan, dan tingkat percabangan. Tinggi akhir generatif, jumlah cabang tambahan, panjang cabang tambahan, dan tingkat percabangan saling berpengaruh satu sama lain untuk mempengaruhi bobot buah per tanaman.

\section{KESIMPULAN}

Jumlah cabang tambahan, panjang cabang tambahan, tingkat percabangan, tinggi akhir generatif, dan jumlah buah per tanaman berkorelasi positif dengan bobot buah total per tanaman Pengaruh langsungjumlah buah per tanaman benar-benar mengukur keeratan hubungan dengan bobot buah per tanaman. Tinggi akhir generatif, jumlah cabang tambahan, panjang cabang tambahan, dan tingkat percabangan saling berpengaruh satu sama lain untuk mempengaruhi bobot buah per tanaman atau produksi.

\section{UCAPAN TERIMAKASIH}

Ucapan terimakasih kepada tim penelitian cabai 2018 (Zora Adlina, Julianto Imantaka, Aulia Indah Pratiwi, Ayu Satia Haini, dan M. Adi Riwanda) yang telah banyak membantu dan memberikan masukan, kritik dan saran yang membangun didalam penyelesaian penelitian.

\section{DAFTAR PUSTAKA}

Aditya, A., K. Hendarto., D. Pangaribuan., dan K.F. Hidayat. 2013. Pengaruh penggunaan mulsa plastik hitam perak dan jerami padi terhadap pertumbuhan dan produksi tanaman cabai merah (Capsicum annum L.) di dataran tinggi. Jurnal Agrotek Tropika. 1 (2) : 147-152.

Badan Pusat Statistik. 2017. Produksi Cabai Nasional. Lampung. Diakses tanggal 23 Oktober 2018

Lelang, M.A. 2017. Uji korelasi dan analisis lintas terhadap karakter komponen pertumbuhan dan karakter hasil tanaman tomat (Lycopersicum esculentum, Mill). Jurnal Pertanian Konservasi Lahan kering 2 (2) : 33-35.

Murniati, N. S. Setyono., dan A.A. Sjarif. 2013. Analisis korelasi dan sidik lintas peubah pertumbuhan terhadap produksi cabai merah (Capsicum annuum L.). Jurnal Pertanian. $3(2): 111-122$.

Muzaiyanah, S dan G.W.A. Santoso. 2016. Hubungan Beberapa Karakter Agronomi terhadap Hasil Kedelai Toleran Kekeringan. (Prosiding Seminar Hasil Penelitian Tanaman Aneka Kacang dan Umbi). Malang.

Purba, K.R., E.S. Bayu, dan I. Nuriadi. 2013.Induksi mutasi radiasi sinar gamma pada beberapa varietas kedelai hitam (Glycine max (L.) Merrill). Jurnal Online Agroekoteknologi, 1 (2) : $154-165$.

Rofidah, N. I., I. Yulianah., dan Respartijarti. 2018. Korelasi antara komponen hasil dengan hasil pada populasi F6 Tanaman cabai merah besar (Capsicum anuum L.). Jurnal Produksi Tanaman. 6 (2) : 230 - 235. 
Singh, R.K., danB.D. Chaudhary. 1979. Biometrical Methods in Quantitatif Genetic Analysis. Kalyani Publishers.Ludhiana-New Delhi.288 hlm.

Sidiq, A.R.F., M. Syukur., dan Marwiyah, S. 2017. Pendugaan parameter genetik dan seleksi karakter kuantitatif cabai rawit (Capsicum annuum L.) populasi F3. Jurnal Bul. Agrohorti 5 (2): 213 - 225

Sulassih, M. Syukur., A. Sobir., A. Maharijaya., Hakim dan Ratih. 2017. Karakterisasi lima galur cabai dalam rangka pendaftaran varietas hasil pemuliaan. Jurnal Hortikultura. 1 (1) : 16 23.

Widiatmiko, G, W.A. Purwantoro., dan P. Basunanda. 2016. Analisis genetik F2 persilangan cabai (Capsicum annum L.) 'JALAPENO' dengan 'TRICOLOR VARIEGATA'. Jurnal Vegetalika. 5(2): 26-37

Yunianti, R., S. Sastrosumarjo., S. Sujiprihat., M. Surahman., dan S.H. Hidayat. 2010. Kriteria Seleksi untuk Perakitan Varietas Cabai Tahan Phytophthora capsici Leonian. J. Agron. Indonesia 38 (2) : 122 - 129 